\title{
Study of correlation between placental morphology and adverse perinatal outcome in different conditions affecting pregnancy
}

\author{
Manik Sirpurkar', Vaibhav Prakash Anjankar ${ }^{2 *}$
}

\begin{abstract}
${ }^{1}$ Department of Obstetrics and Gynaecology, ${ }^{2}$ Department of Anatomy, Chiaryu Medical College and Hospital, Bhopal-462030, Madhyapradesh, India
\end{abstract}

Received: 19 June 2015

Revised: 26 June 2015

Accepted: 10 July 2015

\section{*Correspondence:}

Dr. Vaibhav Prakash Anjankar,

E-mail: vaibhav_anjankar@yahoo.co.in

Copyright: () the author(s), publisher and licensee Medip Academy. This is an open-access article distributed under the terms of the Creative Commons Attribution Non-Commercial License, which permits unrestricted non-commercial use, distribution, and reproduction in any medium, provided the original work is properly cited.

\begin{abstract}
Background: Placenta acts as a mirror which reflects intrauterine status of fetus. Placenta is considered as a leading cause of maternal and perinatal mortality and important factor affecting foetal growth which is generally associated with placental insufficiency. Pregnancy complications like hypertension or gestational diabetes are reflected macroscopically and microscopically in the placenta.

Methods: The study was carried out on 129 placentae which were divided into four groups- normal, pregnancy induced hypertension, anaemia and diabetes mellitus. The various parameters were studied like placental weight, placental surface area, foetal birth weight, placental coefficient, feto-placental weight ratio, foetal outcome in the form of still birth or alive.

Results: It was observed that placental weight was quite low in PIH group than normal. Conversely it was on higher side in Anaemia and Diabetes group. Birth weight of babies show marked reduction in PIH group and Anaemia group, but it is increased in diabetic group. In normal group, stillbirth was observed in $3.33 \%$ deliveries. In conditions complicating pregnancy the percentage of still birth is comparatively higher.

Conclusions: These conditions also affect the perinatal outcome. Placental parameters are also altered along with foetal parameters like foetal weight. So the diagnosis of such risk factors in pregnancies during antenatal period will improve the outcome.
\end{abstract}

Keywords: Insufficieny, Macroscopically, Perinatal, Coefficient

\section{INTRODUCTION}

Placenta is a matter of interest and curiosity for ages for many anatomists, embryologists and obstetricians because of its incomparable importance in the intrauterine development of human being. Placenta acts as a mirror which reflects intrauterine status of fetus. It is the most accurate record of infant's prenatal experiences, so study of placenta and umbilical cord gives valuable clues in cases of adverse fetal outcome. ${ }^{1}$ Placenta is considered as a leading cause of maternal and perinatal mortality ${ }^{2}$ and important factor affecting foetal growth which is generally associated with placental insufficiency. ${ }^{2}$ Pregnancy complications like hypertension or gestational diabetes are reflected macroscopically and microscopically in the placenta. ${ }^{4}$

Adverse perinatal outcome is observed in pregnancies which are complicated by one or more conditions. Commonly observed complications are hypertensive disorders, diabetes, twins, etc. Placenta acts as a mirror which reflects intrauterine status of a foetus. It is the most accurate record of infant's prenatal experiences, so study of placenta gives valuable clues in cases of adverse foetal outcome. ${ }^{1}$ 
In this study we tried to compare the parameters which affect the status of the foetus, and are supposed to alter the morphology of placenta.

\section{METHODS}

This study was conducted on the 129 placentae obtained from the labor rooms and operation theatres of Obstetrics department of our medical college Hospital. The study was approved by Institutional ethical committee. Placentae immediately after delivery were transferred to Research Laboratory of Anatomy department where details were noted. Gross abnormalities of cords and membranes if present, were noted. An accurate weighing was done by trimming off all membranes and cutting umbilical cord $5 \mathrm{~cm}$ from its insertion on the placenta. Superficial vessels were drained off the residual blood. Adhered blood clots were removed and placenta was washed under running tap water, dried with the help of blotting paper, weighed in a weighing machine. Weight was noted in grams.

For calculating surface area of the placenta, diameter of the placenta was measured with the measuring scale. At first, the maximum diameter was measured with a metallic scale graduated in centimeters $(\mathrm{cm})$. Then a second maximum diameter was taken at right angles to the first one. The mean of two measurements was considered as the diameter of the placenta expressed in centimeters. The radius is calculated from diameter. ${ }^{3}$

Formula for Surface area of the placenta $=\pi r^{2}$, where

$$
\pi-3.14
$$

The maternal surface of the placenta was observed by placing the placenta in the white enamel tray and numbers of cotyledons were measured and whether any abnormality in the form of infarction and calcification were examined on the both surfaces of placenta by magnifying lens.

After the examination of placenta and umbilical cord, weight of newborn baby was obtained, foeto-placental weight ratio calculated. Placental coefficient was calculated by dividing placental weight by birth weight of the baby.

Out of total 129 placentae studied, we divided it in four categories according to the risk factors and clinical diagnosis of pregnant women. Diagnosis was done based on the clinical examination done by senior faculty members of the department (associate professors or professors) and laboratory investigations. The four categories were- normal patients without any complications, patients with pregnancy induced hypertension $(\mathrm{PIH})$, patients with anaemia and patients with diabetes mellitus.

Continuous variables were presented as mean \pm standard deviation. Categorical variables were expressed in percentages. $\mathrm{P}<0.05$ was considered as statistically significant. Data was analyzed on statistical software Graph Pad Prism 5.01.

\section{RESULTS}

The mean placental weight was found to be $486 \pm 124 \mathrm{gm}$ in normal group, $398 \pm 98$ gm in PIH group, $504 \pm 133$ gm in anaemia group and $547 \pm 138 \mathrm{gm}$ in diabetic group. It was observed that placental weight was quiet low in PIH group than normal. Conversely it was on higher side in Anaemia and Diabetes group.

Placental surface area as observed in different groups is also shown in table I. it was markedly increases in Anaemia group and Diabetes group. Birth weight of babies show marked reduction in PIH group and Anaemia group, but it is increased in diabetic group.

Birth weight of babies was the most important parameter in our study. We observed that foetal birth weight is significantly reduced in PIH and anaemia groups compared to normal group. On the other hand it was much higher in diabetes group (Table 1).

Table 1: Parameters observed in different groups.

\begin{tabular}{|llll|l|}
\hline & $\begin{array}{l}\text { Normal } \\
\text { Group } \\
\mathrm{n}=30\end{array}$ & $\begin{array}{l}\text { PIH } \\
\text { Group } \\
\mathrm{n}=33\end{array}$ & $\begin{array}{l}\text { Anaemia } \\
\text { Group } \\
\mathrm{n}=38\end{array}$ & $\begin{array}{l}\text { Diabetes } \\
\text { Group } \\
\mathrm{n}=28\end{array}$ \\
\hline $\begin{array}{l}\text { Placental } \\
\text { weight } \\
\text { (Gm) }\end{array}$ & $\begin{array}{l}486 \pm \\
124\end{array}$ & $\begin{array}{l}398 \pm \\
98\end{array}$ & $\begin{array}{l}504 \pm \\
133\end{array}$ & $\begin{array}{l}547 \pm \\
138\end{array}$ \\
\hline $\begin{array}{l}\text { Placental } \\
\text { surface area } \\
\text { (Sq. cm) }\end{array}$ & $\begin{array}{l}223.6 \pm \\
108.5\end{array}$ & $\begin{array}{l}188.4 \pm \\
89.6\end{array}$ & $\begin{array}{l}256.9 \pm \\
154.8\end{array}$ & $\begin{array}{l}286.4 \pm \\
156.9\end{array}$ \\
\hline $\begin{array}{l}\text { Birth weight of } \\
\text { babies } \\
\text { (Gm) }\end{array}$ & $2865 \pm$ & $2267 \pm$ & $2262 \pm$ & $3208 \pm$ \\
\hline $\begin{array}{l}\text { Placental } \\
\text { coefficient }\end{array}$ & 0.170 & 168 & 157 & 189 \\
\hline $\begin{array}{l}\text { Feto-placental } \\
\text { weight ratio }\end{array}$ & 5.90 & 5.70 & 4.49 & 5.86 \\
\hline
\end{tabular}

Table II is showing the foetal outcome in the form of still birth or alive in different categories. In normal group, stillbirth was observed in $3.33 \%$ deliveries. In conditions complicating pregnancy the percentage of still birth is comparatively higher.

Table 2: Foetal outcome in different groups.

\begin{tabular}{|lllll|}
\hline & $\begin{array}{l}\text { Normal } \\
\text { Group } \\
n=30\end{array}$ & $\begin{array}{l}\text { PIH } \\
\text { Group } \\
\mathbf{n}=33\end{array}$ & $\begin{array}{l}\text { Anaemia } \\
\text { Group } \\
\mathbf{n}=38\end{array}$ & $\begin{array}{l}\text { Diabetes } \\
\text { Group } \\
\text { n }=28\end{array}$ \\
\hline Alive & 29 & 28 & 34 & 24 \\
& $(96.67 \%)$ & $(84.85 \%)$ & $(89.47)$ & $(85.71 \%)$ \\
\hline Still & 01 & 05 & 04 & 04 \\
birth & $(3.33 \%)$ & $(15.15 \%)$ & $(10.53 \%)$ & $(14.29 \%)$ \\
\hline
\end{tabular}




\section{DISCUSSION}

The placenta is said to be a characteristic feature of eutherian or "placental" mammals that connects the developing foetus to the uterine wall to allow nutrient uptake, waste elimination and gas exchange through mothers blood supply ${ }^{3}$. Several studies had conducted in the past regarding the morphology of the placenta. In this study, we tried to compare morphological findings of placenta in different conditions complicating pregnancy like pregnancy induced hypertension, gestational diabetes mellitus and anaemia. We also compared the perinatal outcome (alive or still birth) in these conditions.

We noticed reduction in placental weight in PIH group (398 $\pm 98 \mathrm{gm})$ and increased placental weight in anaemia and diabetes groups. The possible explanation can be hypoxia due to anemia and compensatory increase in blood flow which leads to increase in placental weight in anaemia. The weight gain in placentae of diabetic mothers may be attributed to macrosomia and compensatory hyperplasia ${ }^{3}$. Similar findings in diabetic placentae was observed by Pankaj saini et al $(2015)^{6}$, Saha et al $(2014)^{7}$, Ashfaq et al $(2005)^{8}$. The reduced placental weight in hypertensive group may be attributed to reduced blood flow due to ischaemic changes in the vessels ${ }^{1}$. Same findings were also observed by Anjankar et al $(2014)^{1}$.

Birth weight of babies was reduced in PIH and Anaemia groups in our study, and increased in diabetes group. The weight gain in placentae of diabetic mothers may be attributed to macrosomia and compensatory hyperplasia ${ }^{6}$. This macrosmiamay be attributed to fetal hyperinsulenemia in response to hyperglycaemia in fetuses of diabetic mothers (Queenan JT) ${ }^{9}$. Reduced birth weight in PIH group was noted by Anjankar et al (2014) ${ }^{1}$, Majumdar et al (2005) ${ }^{10}$, Udainia \& Jain $(2001)^{11}$.

Thomson et al (1969) ${ }^{12}$ stated that for the evaluation of foetus, weight of the placenta is not enough, but the foeto-placental ratio is important. Increased foetoplacental ratio in hypertensive pregnancies was previously observed by Thomson et al (1969) ${ }^{12}$, Saigal et al (1969) ${ }^{13}$, Gunapriya Raghunath et al (2011) ${ }^{14}$ and Anjankar et $\mathrm{al}^{1}$. Decreased foeto-placental weight ratio was observed Rath et $\mathrm{al}^{15}$.

As shown in table II, stillbirths are more common in PIH group (15.15\%), Anaemia group (10.53\%) and Diabetes group (14.29\%) as compared to normal pregnancies $(3.33 \%)$ which is quiet obvious as these conditions are known to affect the perinatal outcome.

\section{CONCLUSION}

Pregnancy is highly precious for every couple but presence of risk factors in the form of pregnancy induced hypertension, anaemia or diabetes complicates the pregnancy. These conditions also affect the perinatal outcome. Placental parameters are also altered along with foetal parameters like foetal weight. So the diagnosis of such risk factors in pregnancies during antenatal period will improve the outcome.

\section{REFERENCES}

1. Anjankar V, et al. Placental Morphometry in Toxaemia of Pregnancy. Scholars Journal of Applied Medical Sciences. 2014;2(1B):205-8.

2. Roberts JM and Cooper DW. Preeclampsia trio. Pathogenesis and genetics of preeclampsia. The Lancet. 2001;357:53-6.

3. Sengupta K. Shamim A, Khandekar AR and Mahamuda B. Morphological changes of placenta in preeclampsia. Bangladesh Journal of Anatomy. 2009;7(1):49-54.

4. Londhe PS and Mane AB. Morphometric study of placenta and its correlation in normal and hypertensive pregnancies. International Jr of Pharma and Biosciences. 2011;2(4):B-429-36.

5. Goswami $\mathrm{P}$, Memon $\mathrm{S}$ and Pardeep K. Morphological, histological and radiological study of calcified placenta and its relation with foetal outcome. IOSR Journal of dental and medical sciences. 2013;7(6):82-8.

6. Pankaj Saini, Jai Prakash Pankaj, Anjali Jain and Gyan Chand Agarwal. Effect of gestational diabetes mellitus on gross morphology of placenta: a comparative study. Int J Anat Res 2015;3(1):889-94.

7. Saha S, Biswas S, Mitra D, Adhikari A and Saha C. Histologic and morphometric study of human placenta in gestational diabetesmellitus. Ital J Anat Embryol. 2014;119(1):1-9.

8. Ashfaq M, Janjua MZ and Channa MA. Effect of gestational diabetes and maternal hypertension on gross morphology of placenta. J Ayub Med Coll Abbottabad. 2005; 17(1):44-4.

9. Queenan JT. Management of high risk pregnancy. 4th ed. England: Blackwell science; 1999; 261-70.

10. Majumdar S, Dasgupta $H$, Bhattacharya $\mathrm{K}$ and Bhattacharya A. A study of placenta in normal and hypertensive pregnancies. J Anat Soc India, 2005; 54(2): 34-8.

11. Udainia A and Jain ML; Morphological study of placenta in pregnancy induced hypertension with its clinical relevance. J Anat Soc India, 2001; 50(1): 24-27.

12. Thomson AM, Billewicz WZ and Hytten FE. The weight of the placenta in relation to birth weight. $\mathrm{J}$ Obst and Gyaecol $\mathrm{Br}$ Commonwealth. 1969;76(10):865-72.

13. Saigal S and Shrivastava JR. Foeto-pacental weight relationship in normal pregnancy and pre-eclampsia- 
eclampsia- acomparative study. Indian paediatrics. 1970;7(2);68-77.

14. Gunapriya Raghunath, Vijayalakshmi and Varsha Shenoy. A study on morphology and morphometry of human placenta and its clinical relevance in a population in Tamilnadu. JCDR. 2011.5(2):282-6.
15. Rath G, Garg K and Sood M. Insertion of umbilical cord on the placenta in hypertensive mother. J Anat Soc India. 2000;49(2):149-52.

Cite this article as: Sirpurkar M, Anjankar VP. Study of correlation between placental morphology and adverse perinatal outcome in different conditions affecting pregnancy. Int J Reprod Contracept Obstet Gynecol 2015;4:1165-8. 